\title{
Understanding nurses' dual practice: a scoping review of what we know and what we still need to ask on nurses holding multiple jobs
}

Giuliano Russo ${ }^{1 *}$ D, Inês Fronteira ${ }^{2}$, Tiago Silva Jesus ${ }^{2}$ and James Buchan ${ }^{2,3}$

\begin{abstract}
Background: Mounting evidence suggests that holding multiple concurrent jobs in public and private (dual practice) is common among health workers in low- as well as high-income countries. Nurses are world's largest health professional workforce and a critical resource for achieving Universal Health Coverage. Nonetheless, little is known about nurses' engagement with dual practice.

Methods: We conducted a scoping review of the literature on nurses' dual practice with the objective of generating hypotheses on its nature and consequences, and define a research agenda on the phenomenon. The Arksey and O'Malley's methodological steps were followed to develop the research questions, identify relevant studies, include/ exclude studies, extract the data, and report the findings. PRISMA guidelines were additionally used to conduct the review and report on results.

Results: Of the initial 194 records identified, a total of 35 met the inclusion criteria for nurses' dual practice; the vast majority (65\%) were peer-reviewed publications, followed by nursing magazine publications (19\%), reports, and doctoral dissertations. Twenty publications focused on high-income countries, 16 on low- or middle-income ones, and two had a multi country perspective.

Although holding multiple jobs not always amounted to dual practice, several ways were found for public-sector nurses to engage concomitantly in public and private employments, in regulated as well as in informal, casual fashions. Some of these forms were reported as particularly prevalent, from over 50\% in Australia, Canada, and the UK, to $28 \%$ in South Africa. The opportunity to increase a meagre salary, but also a dissatisfaction with the main job and the flexibility offered by multiple job-holding arrangements, were among the reported reasons for engaging in these practices.

Discussion and conclusions: Limited and mostly circumstantial evidence exists on nurses' dual practice, with the few existing studies suggesting that the phenomenon is likely to be very common and carry implications for health systems and nurses' welfare worldwide. We offer an agenda for future research to consolidate the existing evidence and to further explore nurses' motivation; without a better understanding of nurse dual practice, this will continue to be a largely 'hidden' element in nursing workforce policy and practice, with an unclear impact on the delivery of care.
\end{abstract}

Keywords: Nurses dual practice, Multiple job-holding, Moonlighting, Human resources for health, Private health sector, Nurses, Casualization of work

\footnotetext{
* Correspondence: g.russo@qmul.ac.uk

${ }^{1}$ Centre for Primary Care and Public Health, Queen Mary University of

London, Yvonne Carter Building, 58 Turner Street, London E1 2AB, United

Kingdom

Full list of author information is available at the end of the article
} 


\section{Background}

Health workers' dual practice has been identified as one of the priority research areas in the human resources for health domain [1]. There is a concern among policymakers and patients alike that simultaneous engagement with public and private sector activities jeopardise the availability of professionals and the quality of services in the public sector and divert patients towards costlier private care, therefore putting at risk the attainment of Universal Health Coverage (UHC) goals [2, 3].

'Dual practice' in the health sector has been defined as health workers' concomitant engagement in public and private sector clinical activities, with the public sector job representing the 'primary' one to which the largest proportion of working hours are allocated [4]. Although very common worldwide, the practice has been traditionally treated with suspicion by the public health and health system research literature, amid fears that it may compromise the supply of public services [5] and encourage absenteeism in public institutions [6], as well as the selection and diversion of patients towards private services [7]. Scholars have highlighted the possible potential benefits of the practice, such as the opportunity it offers to provide a wider range of health services to the population and to retain underpaid workers in the public sector [8]. Others have paid attention to the regulatory aspects [9], with some focusing on the systems' governance and institutions [10] and others on the incentives to be offered to achieve the desired level of service provision $[11,12]$.

Substantial literature exists on physicians' dual practice $[13,14]$, most recently building up evidence on its prevalence, forms, and drivers worldwide [15-17], as well as on modelling possible regulatory frameworks $[12,18]$. However, nurses' engagement in multiple job-holding is, in comparison, less explored, despite preliminary evidence of its high prevalence in high-income [19] as well as in lowincome settings [20], and amid concerns of its impact on the nurses' wellbeing [21].

Nurses and midwives are the world's largest group of health professionals, representing $48 \%$ of the global health workforce, and their role is widely considered critical for the delivery of UHC goals in high- as well as low-income countries [22]. However, the profession has recently come under pressure because of growth of the demand for health services and concomitant scarcity of funds, and the global shifts in the world's health labour market [23]. As the nursing workforce is predominately female, policy options to address nurses' participation in the public and private labour market will need to take gender into account $[24,25]$.

This scoping review sets out to fill this knowledge gap by systematically searching and reviewing the studies conducted on nurses' simultaneous engagement in public and private clinical activities [26]. Its specific objectives are (1) to map out the existing literature on the subject, determining its prevalence and distribution across geographies, publication types (e.g. peer-reviewed, grey), and specific topics addressed; (2) summarise the evidence, perspectives, and specific contents addressed; and (3) propose an agenda to advance research and development activities to first identify and then mitigate any pervasive effects of nurses' dual practices to UHC, based on the scoping review results.

\section{Methods}

A scoping review was conducted to determine the extent and key themes within the literature on nurses' dual practice, as well as to identify areas for future research on the topic. Such knowledge synthesis method is commonly used to address exploratory research questions, to map the existing literature on a field or to preliminarily identify gaps in that literature [26-28]. We used the five Arksey and O'Malley's methodological steps to develop the research questions, identify relevant studies, include/ exclude articles, extract the data, and report the findings [28]. As the methodological guidance for the report of scoping review is still under development, we used the PRISMA guidelines where appropriate [29].

In March 2017, we searched MEDLINE (through PubMed), the ISI Web of Knowledge, Scopus, and the CINHAL Plus with full texts (through EBSCO). We used a set of keywords for the searches and, where appropriate, Medical Subject Headings for nurses combined with keywords and indexed terms related to dual practice (using the Bolean operator 'AND'). Additional file 1 provides full details for the initial search strategy for each of the databases searched. The grey literature also was searched by visiting websites dedicated to nursing and/or health workforce issues. To widen the scope of the review, the searches on databases and grey literature were not filtered for publication date, language, or publication type. Human resources for health experts (named in the Additional file 1) were a priori contacted to provide relevant references on forms of dual practices among nurses. A posteriori (early December 2017), and based on suggestions coming from the peer-review process, we expand the search terms in the database searches (adding the keywords 'temporary employment' and 'multiple employers') to provide a few additional records which were considered for the review results, as well. Iterative rather than strictly streamlined procedures are typical in the process of conducting scoping reviews [26]. A final search strategy included snowballing searches (reference list scanning, author tracking) performed on the articles preliminarily selected. References from databases or other sources were filtered through the same eligibility criteria. 
To be included, studies needed to address explicitly both nurses and dual practice issues. The working definition for the 'nurses' category contained explicit reference in the text to the professional label, with midwives included too. The working definition of dual practice, in turn, referred to concomitant practice in two (or more) distinct clinical services, either in the same or in different healthcare institutions. Public employment was considered the primary job, whereas the secondary (or subsequent) job(s) was considered the one(s) where fewer working hours were spent, periodically or regularly. Alternative labels for dual practice included 'moonlighting,' 'public-private work', 'multiple profit-generating activities', 'dual/multiple job-holding', and 'second jobs'. 'Casualization of work', defined as the process of replacing full-time and regular part-time staff with contract staff employed on an ad hoc basis, is another phenomenon related in many ways to dual practice [30]. As such, papers addressing this form of employment in relation to dual practice were also included.

Documents in English, French, Portuguese, Italian, and Spanish were included. With the exception of journal commentaries, editorials, and letters to the editor, we did not exclude references because of the type of article (such as opinion pieces), study output (e.g. final or preliminary results), countries or world regions, publication status (i.e. both peer-reviewed and grey literature), or publication date. Titles and abstracts were first screened by one of the authors (TJ) and then reviewed in duplicate by the first author (GR), who finally determined the suitability for the full-text review. Full-text review was carried out by one of three authors, all with a research track record in nurse workforce and/or dual practice issues (GR, IF, JB). Any of the authors were able to directly include or exclude papers on the basis of the eligibility criteria; agreement between two or more reviewers was sought for doubtful cases.

Based on the overarching aim of the paper, the preliminary knowledge of the literature, and a priori consultation with health professionals [13], we developed the following set of questions to guide the data extraction for the review:

- What are the forms in which nurses engage in multiple profit-generating activities?

- What are the different features of nurses' multiple job-holding?

- What is the prevalence of this phenomenon in nursing?

- Why do nurses engage in dual practice?

- What are the enablers and barriers for nurses' dual practice?

- What are the personal/ professional drivers and consequences?
- What are the consequences for health systems, specifically for the delivery of quality and safe nursing/health care?

- What are the consequences for nurses' welfare?

- What are the consequences for patients?

- What are health workers', managers', and patients' perceptions around this practice?

Data extraction tables were then purposively built by the research team to collect data on the specific questions above, either using textual data or synthesis of the articles' findings/conclusions. Consistent with the scoping review methodology, the data extraction did not involve quality appraisal or grading of the evidence from the studies.

A conventional form of qualitative content analysis, with coding categories derived directly from the text data, was used to analyse data retrieved for each topic [31]. The first author performed a first synthesis of the extracted material, that was then iteratively edited by two of the other authors (IF, JB) following the themes from the data extraction table.

\section{Findings from the literature review on nurses' dual practice}

From 228 records retrieved, 159 (70\%) were excluded after reviewing their titles and abstracts (Fig. 1). An additional four articles were identified through snowballing search strategies, resulting in a total of 73 full texts assessed for eligibility. Of all these, a total of 35 (48\%) articles finally met the inclusion criteria for addressing dual practices of nurses: 20 using predominantly quantitative methods and 15 using mostly qualitative designs. The vast majority of the studies were in English, with only four published in Portuguese and one in Spanish. Additional file 2 provides spreadsheets for the (a) list of included articles organised by study-type, (b) the data extraction table, and (c) list of articles excluded with the respective reasons.

The vast majority of such documents (65\%) were peerreviewed publications, with the remainder being nursing magazine publications (19\%), reports, and doctoral dissertations. Twenty publications focused on high-income countries (particularly on the USA, UK, Canada, and Australia), 16 on low- and middle-income ones (South Africa, Ethiopia, Iran, and Uganda), and two provided a global view on the phenomenon. Many of the documents $(n=28)$ reported information on the prevalence of the phenomenon, and discussed its different forms (25). Drivers and motivations of nurses' multiple job-holding were the subject of 10 (out of 38) of the documents, while individual and institutional consequences of the practice were discussed in 9 and 12 pieces, respectively. Only seven of the retrieved documents mentioned policy options 


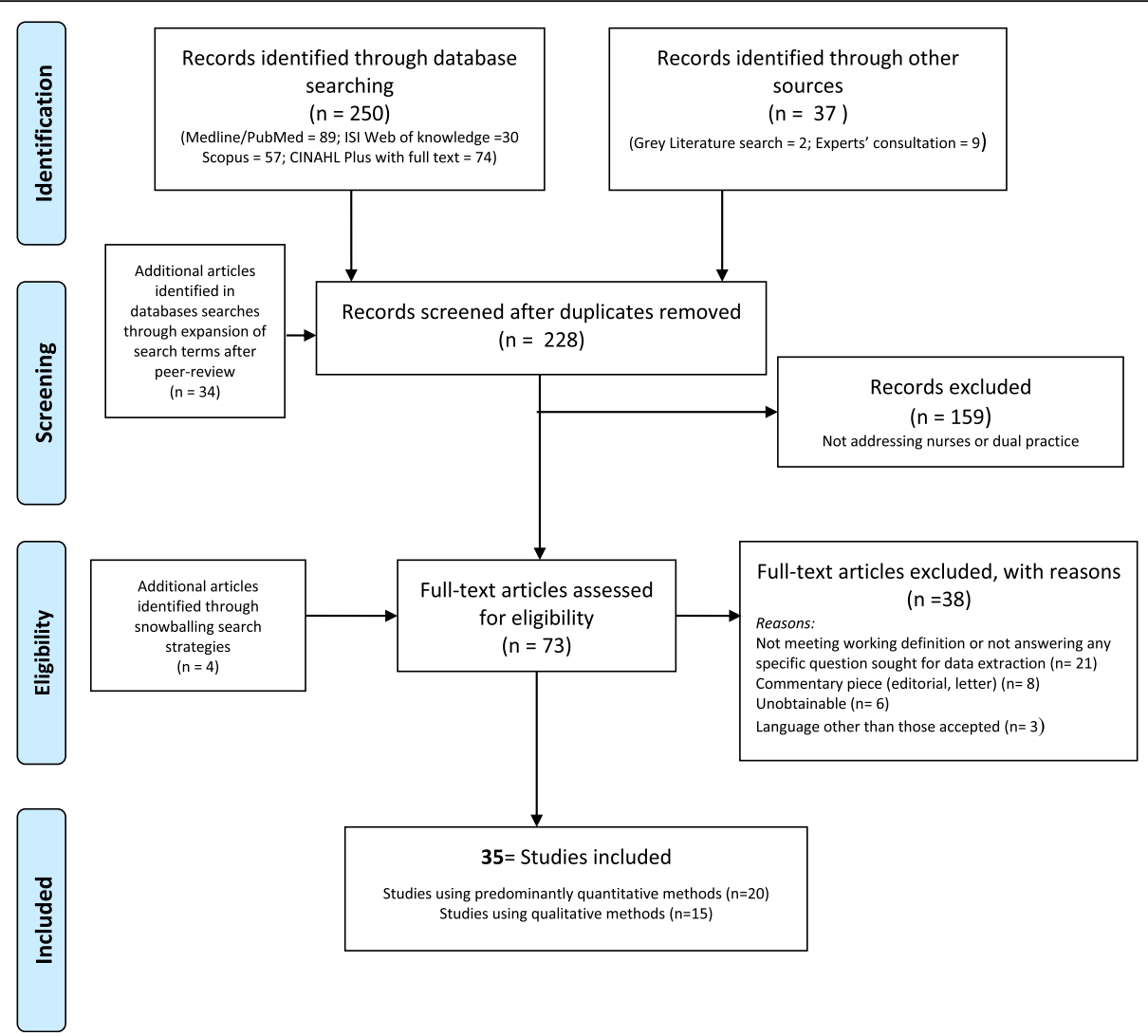

Fig. 1 Flow diagram of the scoping literature review process

associated with nurses' multiple-job holding. Below we present the literature retrieved, organised in sections reflecting the emerging themes.

\section{Forms of nurses' multiple job-holding}

From the documents retrieved, it emerged that nurses' engagement in dual practice can take different forms and shapes, with often blurred boundaries. Some authors mention 'secondary jobs' and 'moonlighting' practices, where public sector nurses engage with the private sector either individually or through an organised nursing services agency [32-34]. Ribera Silva et al. (2009) as well as Gupta et al. (2006) refer generally to 'nurses taking up public or private secondary jobs' in Brazil, Chad, Côte d'Ivoire, Zimbabwe, and Mozambique. A similar operational definition is adopted by Serra et al. to describe nurses' practicing simultaneously in the national healthcare system and for NGOs or private clinics. Publications from HICs at times use the expression 'casualization of work' to describe job insecurity through a lack of a stable contract of employment, but also the practice of working flexibly for public and private health facilities, often through agencies and banks for outsourced nursing services [35-38].
However, a distinction is drawn in the literature between holding multiple jobs concurrently, and dual practice, where the nurse's primary job is in the public sector, and that may be affected in many forms by the simultaneous engagement with other clinical, profitgenerating activities [13]. Three common forms of nurses' dual practice are mentioned, and often used interchangeably, in the literature;

- Primary public sector employment with additional nursing work in the public sector-typically nightly extra shifts in different departments of the same hospital/facility, or other public facilities in the same geographical area [39, 40];

- Primary public sector employment with additional nursing work in the formal or informal private sector-long-hours shifts, or side jobs during spare time/vacation from main employment [34, 41, 42];

- Fixed part-time employment in the public, coupled with multiple flexible contract assignments in public and private sector, often though nurse agencies (referred to as 'casualization') [21, 43, 44].

Some authors report that boundaries between public and private sector employment are often blurred, 
particularly in low-income settings, and that ad hoc classifications of multiple-job holding may be required to capture the essence of the practice for specific countries [2].

\section{Magnitude of the phenomenon}

Although using different definitions of the practice, a number of studies attempted measuring the prevalence of nurses' engagement in multiple job-holding in highincome as well as low- and middle-income countries (see Table 1 below). These are mainly cross-sectional surveys that do not provide data on trends for the phenomenon.

For Australia, Creegan et al. [36] show that $51.7 \%$ of nurses worked part-time in 1997, while in 2011 Batch and Windsor found that the nursing profession had a higher rate of casualization than other professional and highly skilled workforces, and that $47.5 \%$ of nurses were employed in non-standard work [44].

For the UK, Tailby reports that $80 \%$ (of 185000 ) nurses registered with NHS nurse banks had another nursing job, and $60 \%$ worked occasionally or regularly additional shifts paid at bank or agency rates [43]. In a survey among nursing magazines' readers in 2013 [45], 54\% declared taking up extra nursing work, and 10\% another full time job outside nursing; 5 years later, $47 \%$ of the 900 nurses participating in another online magazine readers survey declared engaging in bank and/or agency shifts [37].

A report from the US Bureau of Labor Statistics [46] shows that multiple job-holding has grown steadily over the last decades, that $6.3 \%$ of nurses had multiple jobs in 2014, and that such prevalence was higher for a small sample of male nurses (9.5\%). A 2017 article from Canada [35] provides evidence that $15.8 \%$ of all rural nurses are in casual jobs and that casualization is particularly common among registered nurses and licenced practical nurses (16.5\%), and more common among those nurses living in the north of the country $(20.0 \%)$.

Evidence on the phenomenon from LMICs is substantial too; Gupta et al. report from a multi-country study that nurses dual practice would be more limited than physicians'-the former calculated to be $11 \%$ in Chad; $7 \%$ in Cote d'Ivoire; 26\% in Jamaica; 1\% in Mozambique; $0 \%$ in Sri Lanka; and 7\% in Zimbabwe [41]. In a World Bank study in Ethiopia [34], a similar proportion of a cohort of public sector nurses $(5 \%)$ were found to have secondary jobs 5 years after their initial appointment. Several studies by Rispel and colleagues from South Africa showed the prevalence of different forms of multiple employment to be common (around 28\%) and on the rise among South African nurses [21, 33]. And in Brazil, Portela et al. showed $41.5 \%$ of nurses in two public hospitals to be moonlighters [39].

\section{Drivers and motivation}

A few individual and institutional drivers for the practice are recurrent in the literature. At a personal level, the need to increase overall earnings by supplementing income from main salary is by far the most common, such as in Northern Ireland and elsewhere in the UK-where holding multiple jobs is seen by many nurses as an essential way to increase income $[38,45]$. However, also for a low-income country like Ethiopia where a nurse's salary is typically higher than the country's average Gross Domestic Product (GDP) per capita, Serra et al. report that half of the nurses followed in their study took up a second job to support their families [34].

Flexibility of additional part-time employment seems to be another key factor for Australian and UK nurses, since nursing is a typically female profession, and some female workers have a strong preference for part-time, flexible jobs in comparison to their male peers $[36,43]$. In the surveys in South Africa [21,33], the opportunity for learning new nursing skills, the need to introduce diversity in professional routines, a more stimulating working environment, the quality of supervision, and the ability to select their own working hours were the key reported motivating factors for South African nurses.

At a more institutional level, also in South Africa, the growing demand for nursing services from the private sector is pointed to as the key driver of the phenomenon of casualization of nursing employment. Taking a broader organisational perspective, Batch and Windsor (2014) argue that the 'casualization movement' is really aimed at creating a more flexible, cheaper, and easier to manage the nursing workforce.

\section{Consequences of nurses' multiple job-holding}

No specific study appears to have assessed the impact of nurses' dual practice, although many articles offered hypotheses and interpretations in regard. Generally, health worker's dual practice is regarded unfavourably in the academic literature. McPake et al. argue that, depending on its forms and prevalence, it could hamper the attainment of UHC in some countries [2]. Others report that the associated increased tiredness and lack of alertness for casual workers who work long hours in multiple jobs, as well as their difficulty of communication with resident staff, are reported to substantially increase the risk of clinical accidents [32]. However, a $\mathrm{PhD}$ dissertation work from the USA shows that, on average, nurses with a secondary job tend to work fewer hours in their primary, public employment than their non-moonlighting colleagues [47]. Studies in South Africa suggest that moonlighters are also more likely to take vacation and time out from their main employment to pursue other jobs [21], and intentions to leave 


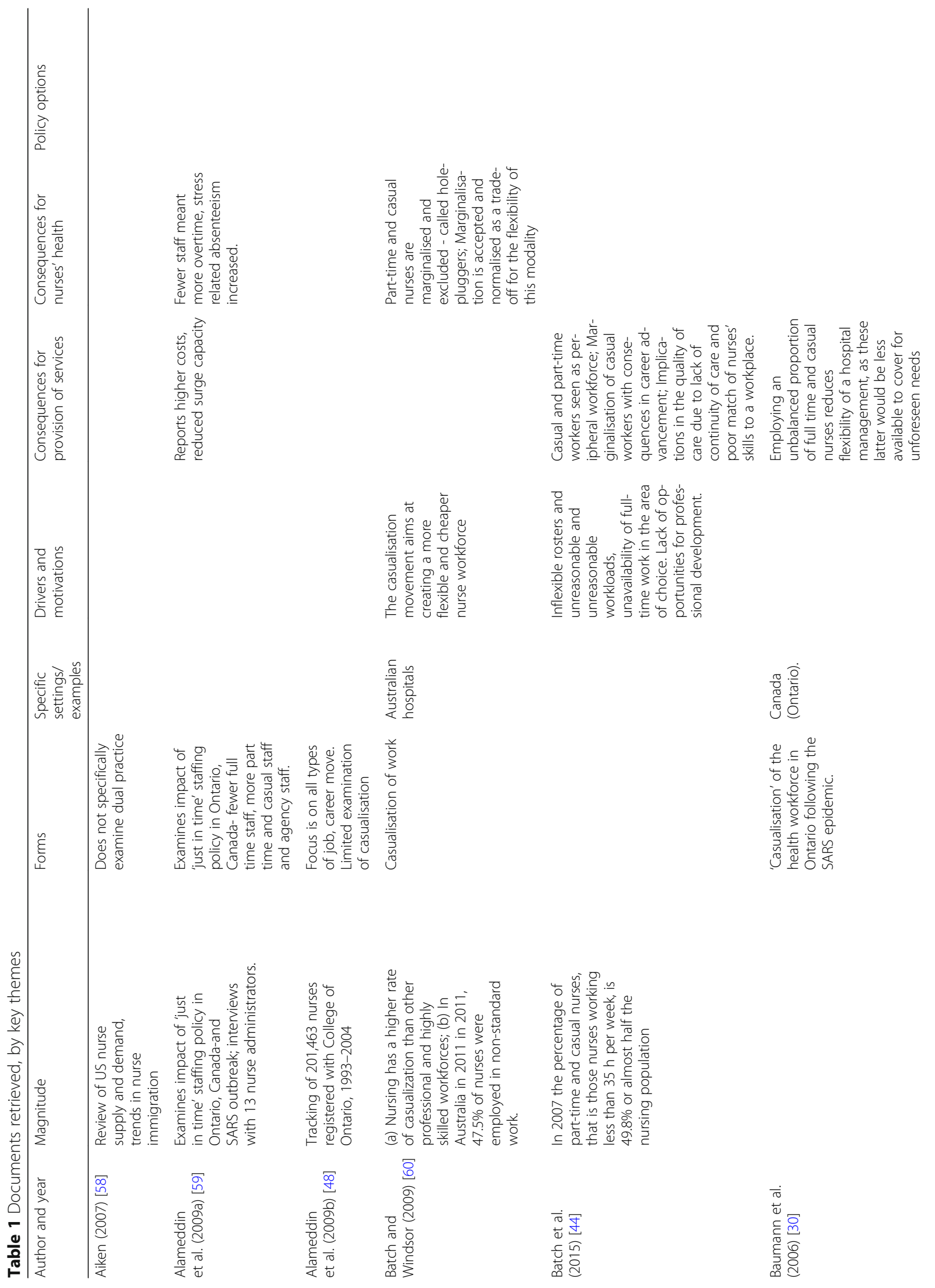




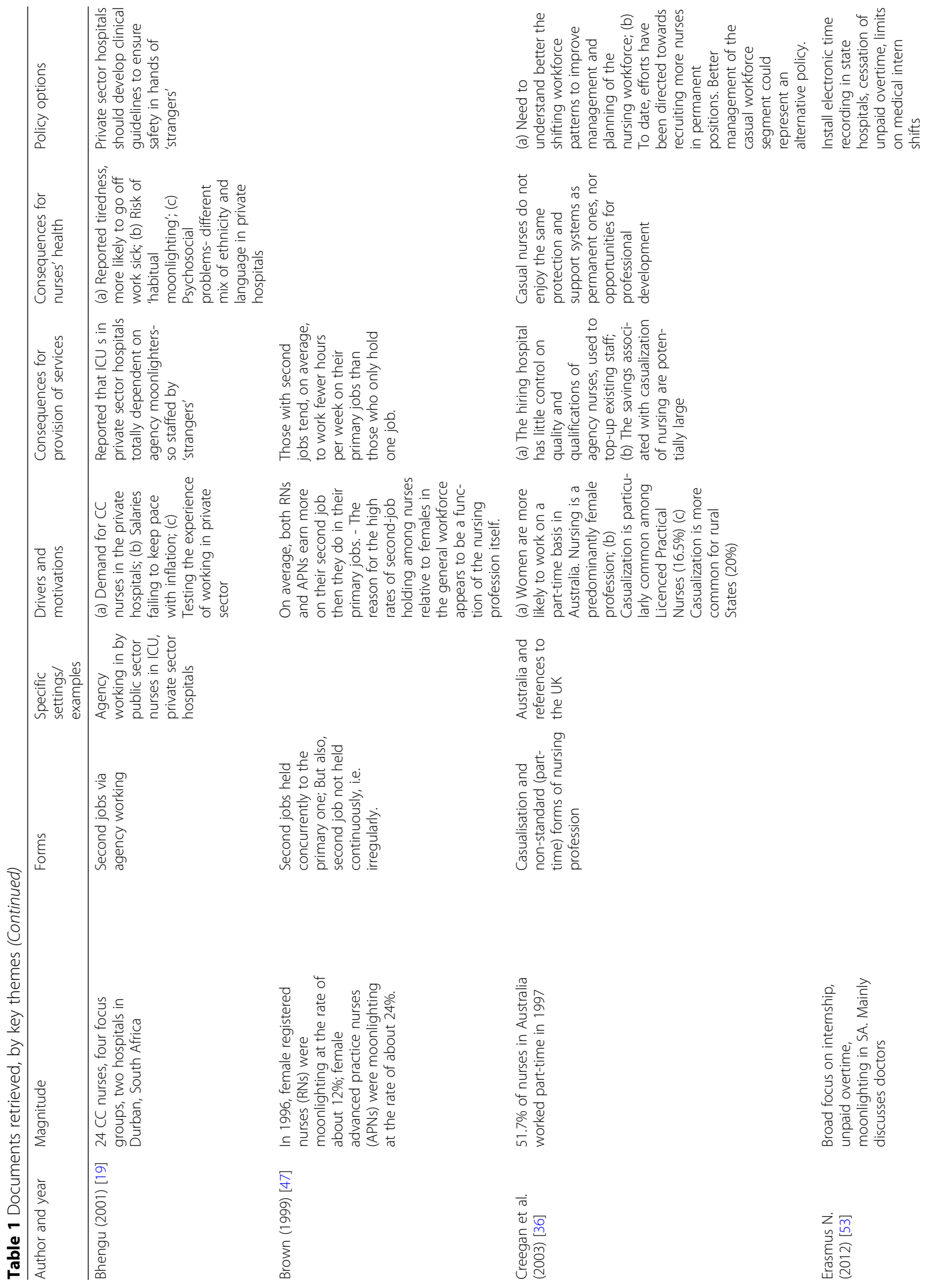




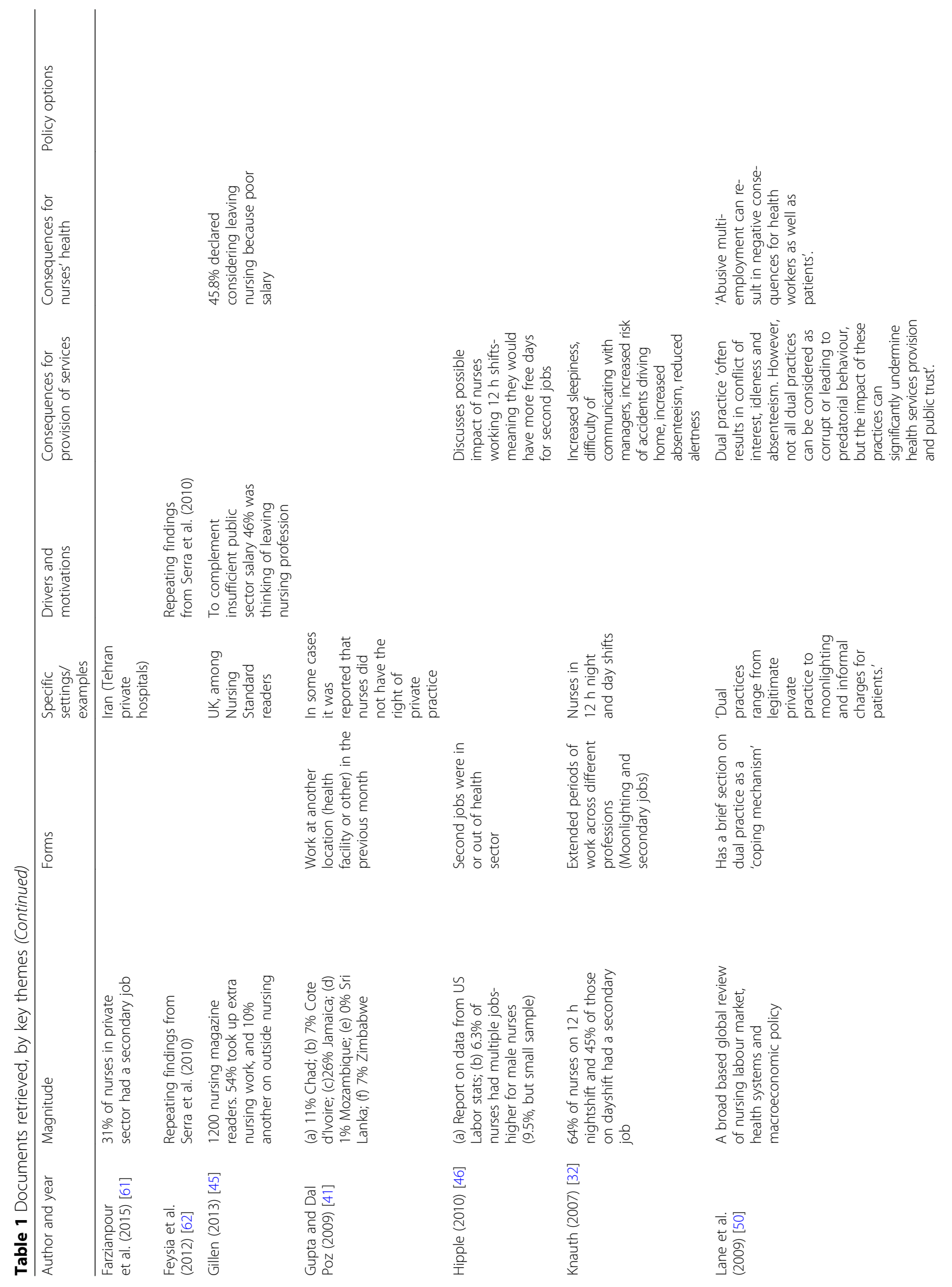




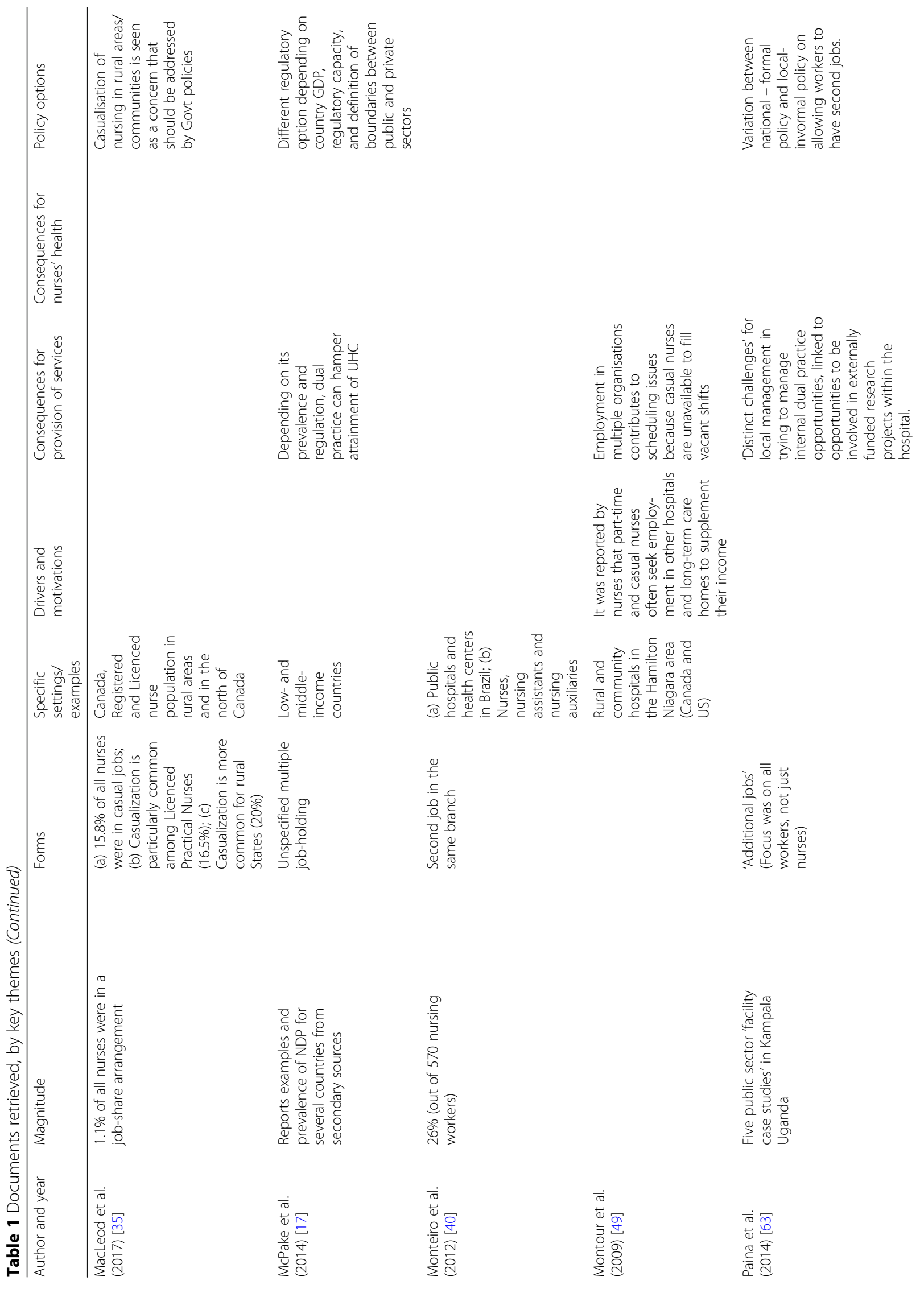




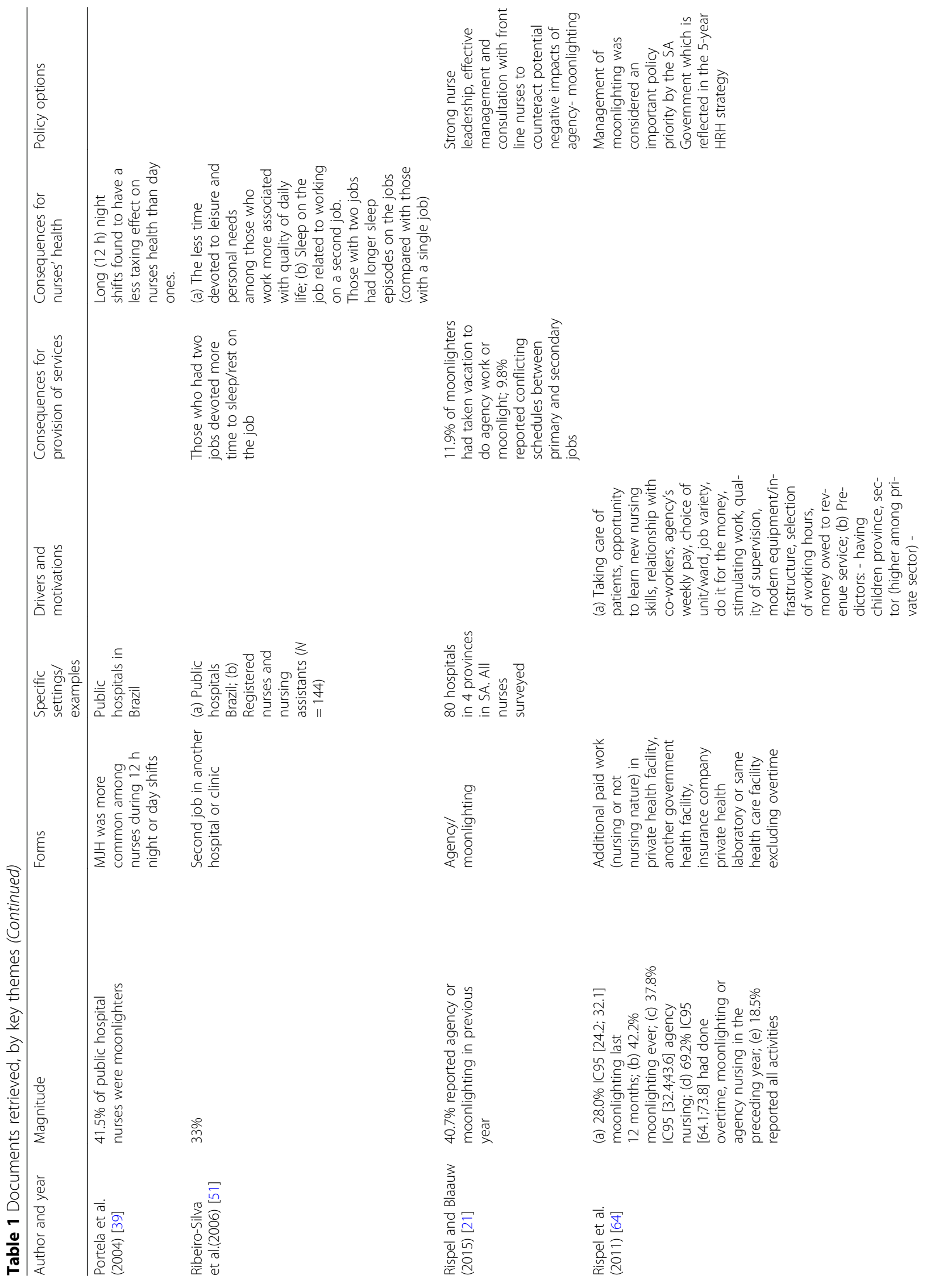




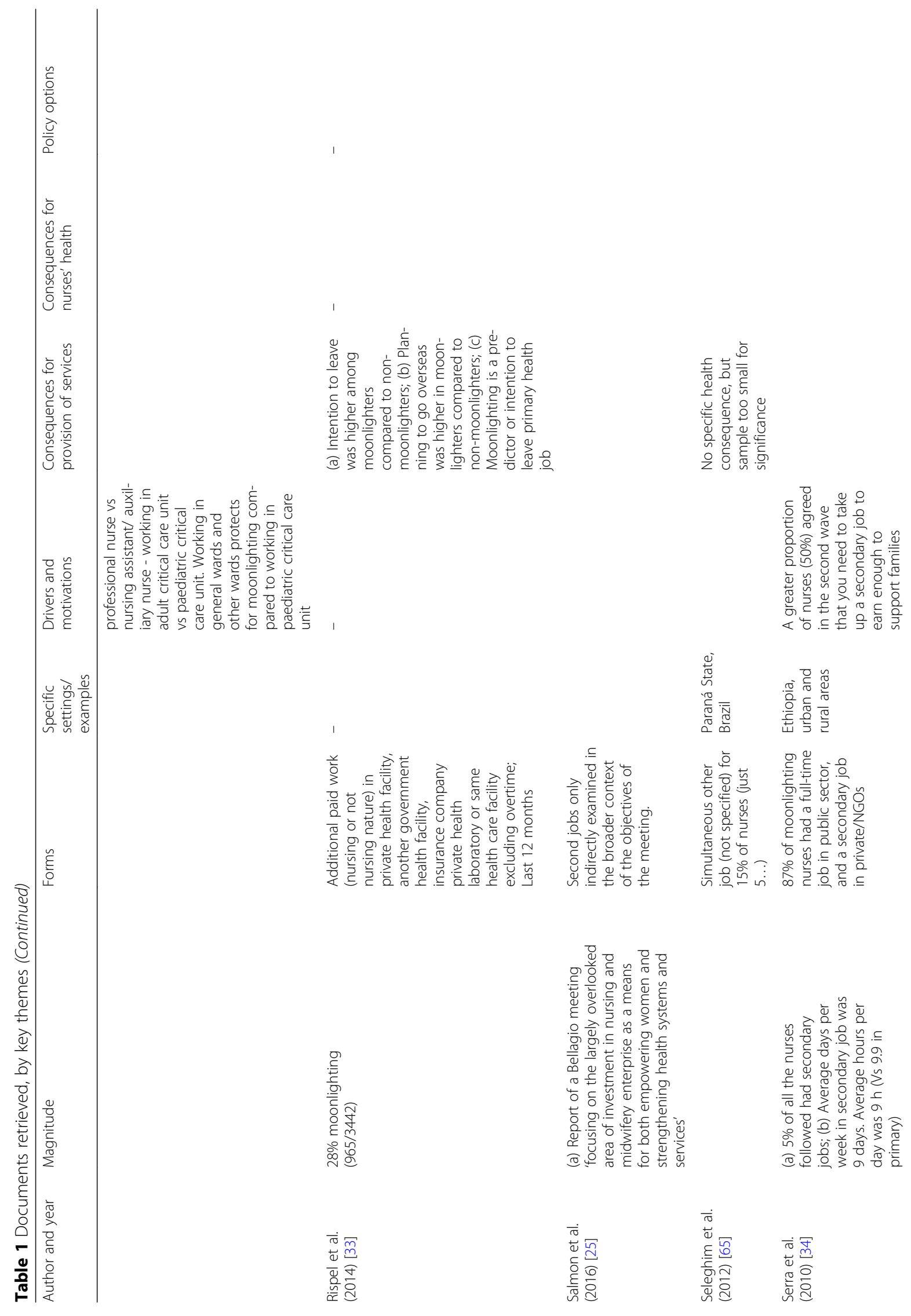




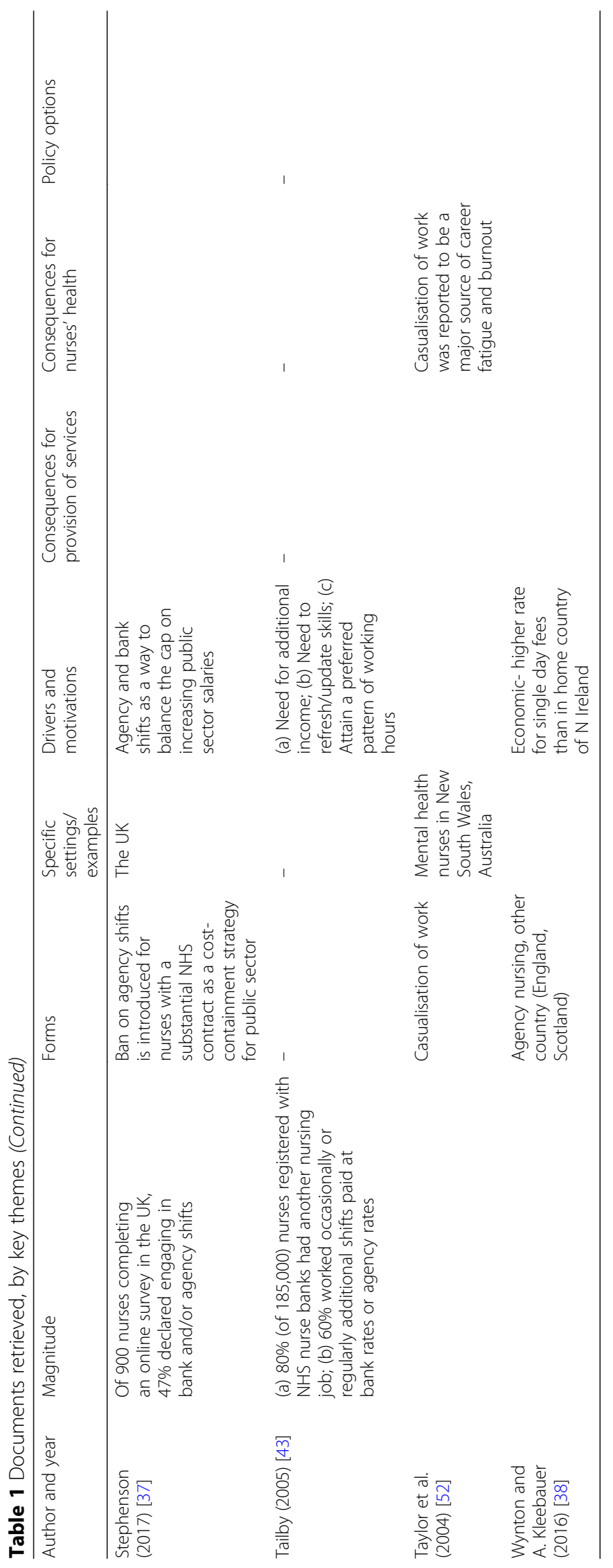


the public sector and/or migrate have been found to be more frequent among them than in their single-job peers [33].

Baumann et al. argue that employing an unbalanced proportion of full-time and casual nurses reduces flexibility of a hospital management, as these latter would be less available to cover for unforeseen needs [30]. In the case of Ontario, Canada's experience with the Severe Acute Respiratory Syndrome (SARS) epidemic, such factors, together with the increased dependence of many hospitals in high-income countries on agency nurses, have been suggested could compromise the system's 'surge capacity', that is, its ability to rapidly scale-up services and response in the face of epidemics [48]. In a qualitative study in rural community hospitals in Canada about the changing nature of nursing work, Montour et al. argue that employment in multiple organisations contributes to scheduling issues because casual nurses are unavailable to fill vacant shifts [49]. And finally, according to some studies, some types of health workers' dual practice can critically undermine health service provision and public trust, as it often entails conflict of interest, idleness, and absenteeism [50].

At a more personal level, Portela et al. show that taking extra shifts can seriously affect nurses' general health and exhaustion levels, with night shifts reported to be less disruptive than day ones [39]. Such findings on sleeping patterns are also echoed by Ribeiro-Silva et al. [51] for hospital nurses in Rio de Janeiro, Brazil, and by Knauth for workers outside the clinical profession [32]. Casualization of work was also identified as a major source of career fatigue and burnout in qualitative interviews with nurses in Australia [52]. Marginalisation and exclusion of part-timers by their peers was also reported to be a major source of dissatisfaction and frustration in an ethnographic study on Australian nurses [44].

As a positive individual consequence, nurses were reported to value highly the opportunity dual work offers to complement meagre public salaries in high-income countries [45] and to support extended families in lowincome ones [34]; in the USA in 1999, nurses earned more in their secondary job than in their primary employment [47]. Flexible working hours is another characteristics that nurses would find particularly attractive in secondary, casual jobs in the UK [43]. In this respect, Creegan et al. suggest that flexible working arrangements would be particularly suited for the predominantly female nursing workforce [36].

\section{Policy options}

Only a minority of the studies retrieved in this review (eight) present and discuss possible policy options for managing, regulating, or controlling the practice. McPake et al. [2] link the choice of policy measures to the prevalence of the practice and to the country's regulatory capacity. Rispel et al. [21] highlight managing moonlighters as a key human resource for health strategy in South Africa; consultation with frontline nurses to counteract the practice's negative impact is suggested as a possible policy option.

Electronic time recording, cessation of unpaid overtime, and controls over the number of shifts are put forward as alternative measures by other authors [53], while developing clinical guidelines for hospitals to ensure safety of services 'in the hands of strangers' has been called for as a possible institutional measure. Other scholars have argued for the need for a better understanding of dual practice patterns, in recognition of the fact that more effective planning and management of a flexible workforce could represent a more suitable solution than prohibition [36].

\section{Discussion}

Our review revealed that nurses engage in multiple jobholding activities, with varying forms and prevalence in high-income as well as in low-income countries. The practice appears to be driven by multiple, complex, and varying factors beyond the obvious economic motif, and to have non-trivial consequences, particularly for nurses' welfare, organisation of health services, and health labour market. Despite its prevalence and relevance, a surprising paucity of studies was found on nurses' dual practice, and very few policy options have been outlined in the literature to address the phenomenon.

Although in the nursing profession holding simultaneously multiple jobs cannot be necessarily considered as dual practice, the two areas often overlap, in shapes of poorly demarcated contours. Consistently with what is observed for other professions, more than one way seems to exist for nurses to engage with dual practice, both in regulated and informal, casual fashions. This may at least in part explain why the practice has been under-reported and little regulated through the years, with some of its forms driven underground or even considered illegal in some countries [34], and other forms-such as the 'casualization' of nursing services-only recently having come to the fore in the context of rapidly evolving health labour markets [33]. This absence of usable datasets would call for primary research to be conducted to, first, explore through qualitative research the specificities of the phenomenon and, second, to measure them quantitatively.

Unsurprisingly, our review of the available evidence appears to show that economic considerations are not the sole driver for nurses taking on simultaneous multiple jobs $[33,54]$. A basic dissatisfaction with the limited range of duties performed in their main job, limited opportunities for development, or availability of time 
made possible by night shift arrangements, are other important factors that may help explain such a decision. Although much effort has been devoted in the past to understanding nurses' burnout $[55,56]$, surprisingly little attention has been given to the tendency to take on additional work in presence of an already heavy workload.

In contrast to the comparatively better understood physician dual practice, the limited evidence reviewed suggests that nurses' dual practice is more likely to be bounded by the very nature of their jobs than it is for physicians, as typically nurses have limited autonomy and tend to work as part of a team, rather than as individual providers. On this basis, a hypothesis could be made that, while nurses are more likely to be part of an established team in their main (public sector) job, second jobs are often taken up as individuals, as agency nurses for one shift, or private home care visits.

Nurses' personal characteristics also appear to shape forms and extent of the practice in any one country. Since taking up additional work in the private sector may be financially rewarding, but will also add to overall workload and may not necessarily increase career prospects, younger and comparatively lower paid nurses seem to be the ones likely to engage more in the practice $[35,39]$. As a compounding factor, as nurses are predominantly female and often perform a disproportionate share of child-rearing and care for elderly or disabled relatives' duties, we may speculate that having dependents will likely decrease their ability to take up additional hours, unless the additional income generated can compensate for any additional child care costs.

The evidence available suggests that the consequences of this phenomenon are not negligible, particularly for the health of those nurses ending up working longer hours and hospital shifts because of their multiple commitments [39, 51], but also for the organisation of public and private health services facing a more 'casual' and less-committed kind of workforce [21]. Interestingly, the most recent literature on nursing and midwifery enterprises $[24,25]$ recognises this limitation and may lay the grounds for a different type of engagement of nursing staff with private sector activities. We also did not find any evidence regarding the importance of economic considerations of nurses' dual practice, or of any difference between higher and lower income countries; as we suspect the implications of such practice may have substantial repercussions on the health labour market, this could represent an area of future research.

This paper is based on a scoping exercise and so has limitations. The limited and often incomplete evidence made it difficult to be certain if dual practice is a factor of relevance in all health systems worldwide, if it is a major issue for nurse labour market participation, and its overall impact on the provision of care. With respect to the latter, this may be because some aspects of dual practice are on the margins of 'formal' work and may go unrecognised by formal systems of employment and regulation.

All of the above call for a deeper understanding of the phenomenon, with the objective of better harnessing the changing nurses' workforce worldwide. Following our review, the core elements of the required research agenda on nurse dual practice appear to be three-fold. First, further research is needed to systematically explore the nature, extent, and impact of nurse dual practice in different systems and countries; this can be achieved through the analysis of employment and professional register/association data sets where these exist, or by adhoc surveys of nurses and/ or workplaces. Analysis of specific data sets in some countries (e.g. such as the Current Population Census [57] and the Integrated Public Use Microdata Series the United Sates; Labour Force Surveys; and professional registries) may provide more evidence on prevalence of dual practice and some of its main forms.

Secondly, there is a need for developing a more informed picture of the reasons why nurses take on dual practice, their experiences and preferences of dual practice, and the impact on their broader work/life balance. This can be achieved through a qualitative approach, exploring multiple contexts in high- and low-income settings, and different nursing profiles.

Finally, there is a gap of research that establish the impact of dual practice at the policy level-what is its impact on participation rates, overall nursing hours available in different systems, what are the trends in incidence, what is the impact on nurses, and on the quality of care that is being delivered. Measures could be needed to mitigate the effects of nurses' dual practice to protect the provision of free-of-charge public sector for vulnerable populations. This latter area for policy research is the most complex and challenging to interrogate, but also of potentially great significance. Without a better understanding of nurse dual practice, it will continue to be a largely 'hidden' element in nursing workforce policy and practice, with an unknown level of significance, and an unclear impact on the delivery of care.

\section{Additional files}

Additional file 1: Search terms-database searches. (DOCX 19 kb) Additional file 2: Spreadsheet of papers reviewed. (XLSX $32 \mathrm{~kb}$ )

\section{Abbreviations}

CINHAL: Cumulative Index to Nursing and Allied Health Literature; EBSCO: Elton B. Stephens Co.; GDP: Gross Domestic Product; HRH: Human Resources for Health; ISI: Institute of Scientific Information; LMIC: Low- and middle-income countries; SARS: Severe acute respiratory syndrome; USA: United States of America; UHC: Universal Health Coverage 


\section{Acknowledgements}

N/A

\section{Funding}

No funding was received for this research.

\section{Availability of data and materials}

All the data and information included in this review can be found in the annexes.

\section{Authors' contributions}

GR elaborated the original idea for the study. GR, IF, and JB designed the study. TSJ designed the methodology for the review. GR drafted the manuscript. All authors revised, read, and approved the final manuscript.

\section{Ethics approval and consent to participate} N/A

\section{Consent for publication}

N/A

\section{Competing interests}

The authors declare that they have no competing interests.

\section{Publisher's Note}

Springer Nature remains neutral with regard to jurisdictional claims in published maps and institutional affiliations.

\section{Author details}

${ }^{1}$ Centre for Primary Care and Public Health, Queen Mary University of London, Yvonne Carter Building, 58 Turner Street, London E1 2AB, United Kingdom. ${ }^{2} \mathrm{GHTM}$, Instituto de Higiene e Medicina Tropical, Nova University of Lisbon, Rua da Junqueira 100, Lisbon, Portugal. ${ }^{3}$ School of Health Sciences, Queen Margaret University, Edinburgh EH21 6UU, United Kingdom.

Received: 4 October 2017 Accepted: 9 February 2018

Published online: 22 February 2018

\section{References}

1. Ranson MK, Chopra M, Atkins S, Dal Poz MR, Bennett S. Priorities for research into human resources for health in low- and middle-income countries. Bull World Health Organ. 2010;88:435-43.

2. McPake B, Russo G, Hipgrave D, Hort K, Campbell J. Implications of dual practice for universal health coverage. Bull World Health Organ. 2016;94:142-6. https://doi.org/10.2471/BLT.14.151894.

3. Sousa A, Scheffler RM, Nyoni J, Boerma T. A comprehensive health labour market framework for universal health coverage. Bull World Health Organ. 2013;91:892-4

4. Berman P, Cuizon D. Multiple public-private jobholding of health care providers in developing countries: an exploration of theory and evidence. Issues paper-private sector. London: DfID Health systems resource centre; 2004. http://www.heart-resources.org/wp-content/uploads/2012/10/ Multiple-public-private-jobholding-ofhealthcare-providers.pdf. Accessed 16 July 2013

5. Brekke KR, Sørgard L. Public versus private health care in a national health service. Health Econ. 2007;16:579-601.

6. Eggleston K, Bir A. Physician dual practice. Health Policy Amst Neth. 2006;78: 157-66.

7. Barros PP, Olivella P. Waiting lists and patient selection. J Econ Manag Strategy. 2005;14:623-46.

8. Jan S, Bian Y, Jumpa M, Meng Q, Nyazema N, Prakongsai P, et al. Dual job holding by public sector health professionals in highly resource-constrained settings: problem or solution? Bull World Health Organ. 2005:83:771-6.

9. Kiwanuka SN, Rutebemberwa E, Nalwadda C, Okui O, Ssengooba F, Kinengyere AA, Pariyo GW. Interventions to manage dual practice among health workers. Cochrane Database Syst Rev. 2011;7:CD008405. https://doi. org/10.1002/14651858.CD008405.pub2.

10. García-Prado A, González P. Policy and regulatory responses to dual practice in the health sector. Health Policy Amst Neth. 2007;84:142-52.

11. González P. Should physicians' dual practice be limited? An incentive approach. Health Econ. 2004;13:505-24.
12. González P, Macho-Stadler I. A theoretical approach to dual practice regulations in the health sector. J Health Econ. 2013;32:66-87.

13. Ferrinho P, Van Lerberghe W, Fronteira I, Hipólito F, Biscaia A. Dual practice in the health sector: review of the evidence. Hum Resour Health. 2004;2:14.

14. Socha KZ, Bech M. Physician dual practice: a review of literature. Health Policy. 2011;102:1-7.

15. Russo G, McPake B, Fronteira I, Ferrinho P. Negotiating markets for health: an exploration of physicians' engagement in dual practice in three African capital cities. Health Policy Plan. 2014;29:774-83.

16. Johannessen K-A, Hagen TP. Physicians' engagement in dual practices and the effects on labor supply in public hospitals: results from a register-based study. BMC Health Serv Res. 2014;14:299.

17. McPake B, Russo G, Tseng F-M. How do dual practitioners divide their time? The cases of three African capital cities. Soc Sci Med. 2014;122:113-21.

18. García-Prado A, González P. Whom do physicians work for? An analysis of dual practice in the health sector. J Health Polit Policy Law. 2011:36:265-94.

19. Bhengu BR. Exploring the critical care nurses' experiences regarding moonlighting. Curationis. 2001;24:48-53.

20. Gupta N, Alfano M. Access to non-pecuniary benefits: does gender matter? Evidence from six low- and middle-income countries. Hum Resour Health. 2011;9:25.

21. Rispel LC, Blaauw D. The health system consequences of agency nursing and moonlighting in South Africa. Glob Health Action. 2015;8:26683.

22. WHO. Global Strategy on Human Resources for Health: Workforce 2030 WHO. 2015. http://www.who.int/hrh/resources/globstrathrh-2030/en/. Accessed 1 Mar 2016.

23. McPake B, Scott A, Edoka I. Analyzing markets for health workers: insights from labor and health economics. World Bank Publications; 2014. http:// documents.worldbank.org/curated/en/787041468155118598/Analyzingmarkets-for-health-workersinsights-from-labor-and-health-economics.

24. Pittman P, Salmon ME. Advancing nursing enterprises: a cross-country comparison. Nurs Outlook. 2016;64:24-32.

25. Salmon ME, Maeda A. Investing in nursing and midwifery enterprise to empower women and strengthen health services and systems: an emerging global body of work. Nurs Outlook. 2016;64:7-16. https://doi.org/ 10.1016/j.outlook.2015.11.010.

26. Colquhoun HL, Levac D, O'Brien KK, Straus S, Tricco AC, Perrier L, et al. Scoping reviews: time for clarity in definition, methods, and reporting. J Clin Epidemiol. 2014;67:1291-4.

27. Anderson S, Allen P, Peckham S, Goodwin N. Asking the right questions: scoping studies in the commissioning of research on the organisation and delivery of health services. Health Res Policy Syst. 2008;6:7.

28. Arksey H, O'Malley L. Scooping studies: towards a methodological framework. Int J Soc Res Methodol. 2005;8:19-32.

29. Moher D, Liberati A, Tetzlaff J, Altman DG and PRISMA Group. Preferred Reporting Items for Systematic Reviews and Meta-Analyses: The PRISMA Statement. PLOS Medicine. 6(7) 2009: e1000097. https://doi.org/10.1371/ journal.pmed.1000097.

30. Baumann AO, Blythe JM, Underwood JM. Surge capacity and casualization: human resource issues in the post-SARS health system. Can J Public Health Rev Can Sante Publique. 2006;97:230-2.

31 Hsieh H-F, Shannon SE. Three approaches to qualitative content analysis. Qual Health Res. 2005;15:1277-88.

32 Knauth P. Extended work periods. Ind Health. 2007:45:125-36.

33 Rispel LC, Blaauw D, Chirwa T, de Wet K. Factors influencing agency nursing and moonlighting among nurses in South Africa. Glob Health Action. 2014;7 https://doi.org/10.3402/gha.v7.23585.

34 Serra D, Serneels P, Lindelow M. Discovering the real world. Health workers' career choices and early work experience in Ethiopia. The World Bank: Washington; 2010. http://elibrary.worldbank.org/doi/abs/10.1596/978-08213-8356-8. Accessed 1 Mar 2016

35 MacLeod MLP, Stewart NJ, Kulig JC, Anguish P, Andrews ME, Banner D, et al Nurses who work in rural and remote communities in Canada: a national survey. Hum Resour Health. 2017;15:34.

36 Creegan R, Duffield CM, Forrester K. Casualisation of the nursing workforce in Australia: driving forces and implications. 2003. https://opus.lib.uts.edu.au/ handle/10453/4660. Accessed 6 July 2017.

37 Stephenson J. Exclusive: Survey Reveals Anger and Concern over Agency Rule. Nursing Times. 2017. https://www.nursingtimes.net/news/workforce/ exclusive-survey-reveals-anger-and-concernover-agency-rule/7016870.article. 
38 Wynton L, Kleebauer A. Poor pay forcing Northern Ireland nurses to moonlight across the UK. Nurs Stand R Coll Nurs G B 1987. 2016;30:10.

39 Portela LF, Rotenberg L, Waissmann W. Self-reported health and sleep complaints among nursing personnel working under $12 \mathrm{~h}$ night and day shifts. Chronobiol Int. 2004;21:859-70.

40 Monteiro I, Chillida M de SP, Moreno LC. Work ability among nursing personnel in public hospitals and health centers in Campinas-Brazil. Work Read Mass. 2012;41(Suppl 1):316-9.

41 Gupta N, Dal Poz MR. Assessment of human resources for health using cross-national comparison of facility surveys in six countries. Hum Resour Health. 2009;7:22.

42 McMenamim P. QuikStats-Moonlighting Nurses - ANA Community. http:// www.ananursespace.org/browse/blogs/blogviewer?BlogKey=668883 $\mathrm{d} 2$ c992-4cd5-89d7-68beba531ed0\&ssopc=1. Accessed 16 Feb 2018

43 Tailby S. Agency and bank nursing in the UK National Health Service. Work Employ Soc. 2005;19:369-89.

44 Batch M, Windsor C. Nursing casualization and communication: a critical ethnography. J Adv Nurs. 2015;71:870-80. https://doi.org/10.1111/jan.12557.

45 Gillen S. Nurses make ends meet through extra shifts and payday loans. Nurs Stand. 2013;28:7-7. https://doi.org/10.7748/ns2013.11.28.11.7.s2.

46 Hipple SH. Multiple jobholding over the past two decades: monthly labor review: U.S. Bureau of Labor Statistics. Mon Labor Rev. 2010:21-32.

47 Brown T. Three essays on the labor market for nonphysician clinicians. Berkeley: University of California; 1999.

48 Alameddine M, Baumann A, Laporte A, O'Brien-Pallas L, Levinton C, Onate K, et al. Career trajectories of nurses leaving the hospital sector in Ontario, Canada (1993-2004). J Adv Nurs. 2009;65:1044-53.

49 Montour A, Baumann A, Blythe J, Hunsberger M. The changing nature of nursing work in rural and small community hospitals. Rural Remote Health. 2009;9:1089.

50 Lane C, Fernandes Antunes A, Kingma M. The nursing community, macroeconomic and public finance policies: towards a better understanding. Geneva: The World Health Organization; 2009. http://www. who.int/health_financing/documents/cov-dp_e_09_02-nursing_ macroeconomics/en/. Accessed 7 July 2017

51 Ribeiro-Silva F, Rotenberg L, Soares RE, Pessanha J, Ferreira FL, Oliveira P, et al. Sleep on the job partially compensates for sleep loss in night-shift nurses. Chronobiol Int. 2006;23:1389-99. https://doi.org/10.1080/ 07420520601091931

52 Taylor B, Barling J. Identifying sources and effects of carer fatigue and burnout for mental health nurses: a qualitative approach. Int J Ment Health Nurs. 2004;13:117-25.

53 Erasmus N. Slaves of the state-medical internship and community service in South Africa. South Afr Med J Suid-Afr Tydskr Vir Geneeskd. 2012:102:655-8.

54 Hanson K, Jack W. Health worker preferences for job attributes in Ethiopia: results from a discrete choice experiment. The World Bank; 2008. http:// documents.worldbank.org/curated/en/2008/04/11830852/health-workerpreferences-job-attributes-ethiopia-results-discrete-choice-experiment. Accessed 1 Mar 2016.

55 McHugh MD, Kutney-Lee A, Cimiotti JP, Sloane DM, Aiken LH. Nurses' widespread job dissatisfaction, burnout, and frustration with health benefits signal problems for patient care. Health Aff Proj Hope. 2011;30:202-10.

56 Ribeiro VF, Filho CF, Valenti VE, Ferreira M, de Abreu LC, de Carvalho TD, et al. Prevalence of burnout syndrome in clinical nurses at a hospital of excellence. Int Arch Med. 2014;7:22.

57 US Census Bureau. Current Population Survey (CPS). 2017. http://www. census.gov/programs-surveys/cps.html. Accessed 4 Jan 2017.

58. Aiken LH. U.S. Nurse Labor Market Dynamics Are Key to Global Nurse Sufficiency. Health Serv Res 42, no. Pt 2. 2007;3:1299-1320. https://doi.org/ 10.1111/j.1475-6773.2007.00714.x

59. Alameddine M, Dainty KN, Deber R, Sibbald WJ (Bill). The Intensive Care Unit Work Environment: Current Challenges and Recommendations for the Future. J Crit Care. 2009;24(2):243-48. https://doi.org/10.1016/j.jcrc.2008.03.038.

60. Batch Mary, Barnard A, Windsor C. Who's Talking? Communication and the Casual/Part-Time Nurse: A Literature Review. Contemporary Nurse. August 2009:33(2):20-29.

61. Farzianpour F, Saeadeh Ansari Nosrati, Abbas Rahimi Foroushani, Fateme Hasanpour, Zahra Khakdel Jelodar, Meysam Safi Keykale, Mohammad Bakhtiari, and Niusha Shahidi Sadeghi. Relationship Between Shift Work and Personality Traits of Nurses and Their Coping Strategies. Global Journal of Health Science. 2015;8(5):166-74. https://doi.org/10.5539/gjhs.v8n5p166.
62. Feysia B, Herbst C, Lemma W. The Health Workforce in Ethiopia: Addressing the Remaining Challenges. World Bank Publications, 2012.

63. Paina L, Bennett S, Ssengooba F, Peters DH. Advancing the Application of Systems Thinking in Health: Exploring Dual Practice and Its Management in Kampala, Uganda. Health Research Policy and Systems / BioMed Central. 2014;12(41). https://doi.org/10.1186/1478-4505-12-41.

64. Rispel LC, Armstrong S, Blaauw D, Chirwa T. The Nature and Health System Consequences of Casualisation, Agency Nursing and Moonlighting in South Africa. Technical report. Atlantic Philanthropies. Johannesbourgh, South Africa: Centre for Health Policy School of Public Health University of the Witwatersrand, Johannesburg, 2011.

65. Seleghim MR, Mombelli MA, de Oliveira MLF, Waidman MAP, Marcon SS. Stress Symptoms in Female Nurses Working in Emergency Rooms. Revista Gaúcha de Enfermagem. 2012;33(3):165-73. https://doi.org/10.1590/S198314472012000300022

\section{Submit your next manuscript to BioMed Central and we will help you at every step:}

- We accept pre-submission inquiries

- Our selector tool helps you to find the most relevant journal

- We provide round the clock customer support

- Convenient online submission

- Thorough peer review

- Inclusion in PubMed and all major indexing services

- Maximum visibility for your research

Submit your manuscript at www.biomedcentral.com/submit
) Biomed Central 